TEMPUS Revista en Historia General

Medellín, Colombia / julio-diciembre 2019 / Número 10

ISSN-e: $2422-2178$

Dossier economía moral, agentes y prácticas sociales, siglo XVIII

PATERNALISMO, VIOLENCIA Y

ECONOMÍA MORAL EN LA FRONTERA

AUSTRAL DEL IMPERIO ESPAÑOL

DURANTE LAS CAMPAÑAS MILITARES

CONTRAINSURGENTES, 1813-1822

\author{
PATERNALISM, VIOLENCE AND MORAL ECONOMY ON \\ THE SOUTHERN FRONTIER OF THE SPANISH EMPIRE DURING \\ COUNTER-INSURGENT MILITARY CAMPAIGNS, 1813-1822
}

\author{
Dr. Manuel Ramírez Espíndola ${ }^{1}$ iD \\ Universidad Católica de la Santísima Concepción (Chile)
}

DOI: https://doi.org/10.17533/udea.tempus.n10a06

Cómo citar este artículo en Chicago Manual of Style: Ramírez Espíndola, Manuel. "Paternalismo, violencia y economía moral en la frontera austral del imperio español durante las campañas militares contrainsurgentes, 1813-1822". Tempus Revista en Historia General no. 10 (2019):1-26.

Artículo recibido el 1 de septiembre y aprobado para su publicación el 19 de octubre de 2019.

\footnotetext{
${ }^{1}$ Académico de la Facultad de Comunicación, Historia y Ciencias Sociales de la Universidad Católica de la Santísima Concepción (Chile). Es Doctor en Historia por El Colegio de México, Máster en Historia del Mundo Hispánico por el Consejo Superior de Investigaciones Científicas de Madrid y Profesor de Historia y Geografía por la Universidad de Concepción. Sus líneas de investigación son las guerras de independencia, los ejércitos borbónicos y los circuitos comerciales en la frontera hispano-mapuche durante los siglos XVIII y XIX. Correo electrónico: manuelramirez@ucsc.cl.
} 


\section{Paternalismo, violencia y economía moral en la frontera austral del imperio español durante las campañas militares contrainsurgentes, 1813-1822}

\section{Resumen}

Las acciones militares desplegadas por los virreyes Abascal y Pezuela contra los principales focos de la insurgencia sudamericana estuvieron marcadas por la movilización de sus respectivos componentes locales. En el caso específico del reino de Chile, dichas colectividades no solo conformaron sus propias fuerzas militares, sino que además participaron activamente en el diseño y puesta en escena de la contrarrevolución. La naturaleza de aquella "reacción monarquista", así como las distintas prácticas desplegadas en su seno, nos revelan la existencia de complejas configuraciones sociales en las que diversos sectores vieron en la guerra un mecanismo de acumulación económica -a la vez que una fuente de legitimidad-en un tiempo en el que la monarquía borbónica contaba aún con un amplio aliciente en el imaginario político de aquellas poblaciones. La ponencia analiza las características que revistió este proceso, a través de la reconstrucción de las principales prácticas económicas y fiscales, junto con las redes relacionales que involucraron a los principales protagonistas de la guerra. Por un lado, destacamos las estrategias paternalistas de las autoridades locales y virreinales en el restablecimiento de la autoridad real, situación que convivió con los discursos de la oficialidad en torno a una justificación moral de su accionar.

Palabras clave: Economía moral; frontera hispano-mapuche; guerras de independencia.

\footnotetext{
Abstract

The military actions deployed by the viceroys Abascal and Pezuela against the main centers of the South American insurgency were determined by the mobilization of their respective local components. In the specific case of the kingdom of Chile, these communities not only formed their own military forces. In fact, they participated in the design and staging of the counterrevolution.

The nature of that "monarchist reaction" and the different practices deployed within it, reveal the existence of complex social configurations in which various sectors saw in the
} 


\section{Manuel Ramírez Espíndola}

war a mechanism of economic accumulation -assuming that it was already a source of legitimacy- all this at a time when the Bourbon monarchy had a wide incentive in the political imaginary of those populations. This paper analyzes the characteristics of this process through the reconstruction of the main economic and fiscal practices, together with the relational networks that involved the main protagonists of the war. On the one hand, we highlight the paternalistic strategies of the local and viceregal authorities in the reestablishment of the royal authority, a situation that coexisted with the discourses of the officers around a moral justification of their actions.

Key Words: Moral Economy; Spanish-Mapuche Frontier; Wars of Independence in Spanish America. 


\section{Paternalismo, violencia y economía moral en la frontera austral del imperio español durante las campañas militares contrainsurgentes, 1813-1822}

\section{Introducción}

Durante las décadas de 1810 y 1820 los territorios del antiguo obispado de Concepción, en los confines australes del reino de Chile, fueron el triste escenario de cruentos combates entre los restos del ejército borbónico y las nuevas fuerzas revolucionarias nacidas de la crisis imperial. Si bien estas últimas acabarían haciéndose con el triunfo y la independencia definitiva, los costos de ambos procesos se hicieron sentir fuertemente durante aquel periodo. Tras una década de enfrentamientos, la devastación económica, la indefensión de los ejércitos y la imposibilidad de poner fin al conflicto llevaron a la masificación del bandolerismo y el fenómeno guerrillero, los cuales dejaron una profunda huella en la configuración de aquella región y su proyección a lo largo de la centuria.

La naturaleza y los efectos de aquellas conflagraciones -presentes en distintas zonas del continente- han llamado profundamente la atención de los historiadores, desde el siglo XIX hasta nuestros días. Mientras que la historiografía liberal-positivista puso su atención en la naturaleza y el carácter de sus protagonistas, los economicistas del siglo pasado hicieron lo propio con el estudio de las consecuencias estructurales de la guerra. Con todo, la renovación de la historia social y cultural, particularmente a partir del giro poscolonial y la difusión de los estudios subalternos, han introducido nuevos presupuestos teóricos y metodológicos, los que ciertamente han abierto las perspectivas a la revisión actual de la guerra y sus consecuencias ${ }^{2}$.

En el caso específico de los estudios americanistas, desde la década de 1990 distintas investigaciones han venido cuestionando los basamentos de la historiografía

\footnotetext{
${ }^{2} \mathrm{Al}$ respecto, véase: Jay Kinsbruner, Independence in Spanish America: Civils Wars, Revolutions, and Underdevelopment (Albuquerque: University of New Mexico Press, 2000); Christon Archer (ed.), The Wars of Independence in Spanish America (Wilmington: Jaguar Books, 2000); Anthony McFarlane, War and Independence in Spanish America (New York: Routledge, 2014); Marcela Echeverri, Indian and Slave Royalist in the Age of Revolution: Reform, Revolution, and Royalism in the Northern Andes, 1780-1825 (New York: Cambridge University Press, 2016).
} 


\section{Manuel Ramírez Espíndola}

tradicional, de cara a rescatar la experiencia histórica de los sujetos populares y su impronta en los procesos estructurales que han afectado al continente desde el periodo colonial. Por un lado, subsiste la necesidad de ahondar en las raíces de una "cultura popular", a través del análisis de las distintas representaciones que se han hecho de estos grupos. Sin embargo, también se ha avanzado mucho en la reconstrucción de sus órbitas relacionales, mediante el análisis de sus prácticas e imaginarios ${ }^{3}$.

La propia historiografía chilena ha seguido estos mismos derroteros, experimentando un importante vuelco hacia el estudio de los procesos del mundo popular en la transición de colonia a república, tal y como analizaremos a continuación.

En este sentido, el presente trabajo busca profundizar los análisis que se han hecho en torno al fenómeno guerrillero y los casos de insurrección social que siguieron a la declaración de la independencia de Chile, poniendo especial énfasis a los antecedentes que condujeron a ambas situaciones. Para ello, hacemos una reconstrucción de las prácticas económicas y fiscales desarrolladas durante la primera fase del conflicto bélico, destacando la proyección que estas tuvieron en los años más álgidos del enfrentamiento.

Del mismo modo, cuestionamos algunas idealizaciones que se han hecho respecto a los sujetos populares y, por el contrario, destacamos la estrecha relación que se habría generado entre las autoridades centrales y los mandos medios en la movilización de los sectores subalternos. Ante todo, sostenemos cómo los intereses hegemónicos de los grupos dominantes, destinados a poder cubrir las necesidades materiales y logísticas de sus respectivos ejércitos, estuvieron mediados por la capacidad de cooptar a distintos grupos sociales, para lo cual fortalecieron una serie de estrategias de tipo paternalista y clientelista. Lo anterior habría dado lugar a la formación de toda una generación de

\footnotetext{
${ }^{3}$ Entre las obras más representativas se cuentan: Carlos Aguirre y Charles Walker (eds.), Montoneros, abigeos y malhechores. Criminalidad y violencia en el Perú, siglos XVIII-XX (Lima: Instituto de Cooperación Agraria, 1990); John Fisher, Allan Kuethe y Anthony McFarlane (comps.), Reform and Insurrection in Bourbon New Granada and Perú (Baton Rouge: Louisiana University Press, 1990); Fredrich Katz (comp.), Revuelta, rebelión y revolución. La lucha rural en México, del siglo XVI al XX (México: Ediciones ERA, 1990); Florencia Mallón, Peasant and Nation. The Making of Postcolonial Mexico and Peru (Berkeley: University of California Press, 1995).
} 


\section{Paternalismo, violencia y economía moral en la frontera austral del imperio español durante las campañas militares contrainsurgentes, 1813-1822}

individuos, estrechamente vinculados al ejercicio de la guerra, cuyas redes y niveles de asociatividad no solo estuvieron encaminados a la búsqueda de un incentivo económico, puesto que su accionar se vinculaba además con la defensa de una serie de valores tradicionales y el desarrollo de una cultura política común, la que se expresa en sus discursos.

Nuestro trabajo lo dividimos en tres partes. En primer lugar, analizamos las distintas caracterizaciones que se han hecho en torno a estos sujetos, destacando el papel que han tenido las investigaciones de las últimas décadas. Seguidamente, desarrollamos nuestro análisis sobre las prácticas económicas y fiscales implementadas durante las llamadas guerras de independencia, centrándonos en el desarrollo de estas actividades durante las primeras campañas de la contrainsurgencia y su proyección en los años siguientes. Por último, analizamos la dimensión menos conocida de algunos de los protagonistas de la guerra, a través de la reconstrucción de sus órbitas relacionales y la concurrencia de estas asociaciones durante las fases finales del conflicto.

Resta decir que nuestra investigación se basa fundamentalmente en el análisis de documentación primaria, a través de la revisión de los libros contables de la intendencia militar del ejército monarquista durante el periodo 1813-1816, información que complementamos con el análisis de protocolos notariales, correspondencia oficial, así como de algunas crónicas y memorias del periodo.

\section{De bárbaros a montoneras populares}

Como sostuvo Tulio Halperin Dongui, hace ya más de medio siglo, el despojo y la violencia generadas durante las guerras de independencia dejaron una huella profunda en las generaciones intelectuales del siglo XIX latinoamericano ${ }^{4}$. En el caso chileno, el

\footnotetext{
${ }^{4}$ Tulio Halperin Donghi, Revolución y guerra. Formación de una élite dirigente en la Argentina criolla (Buenos Aires: Siglo XXI, 1972).
} 


\section{Manuel Ramírez Espíndola}

naturalista Claudio Gay fue probablemente el primero en abordar este problema, siempre presente en sus obras, aunque especialmente visible en sus reconstrucciones etnográficas y su propio trabajo de campo en la frontera araucana ${ }^{5}$. La labor pionera de Gay fue posteriormente ahondada por algunos de sus discípulos, como fue el caso de Benjamín Vicuña Mackenna y Diego Barros Arana, el primero de los cuales popularizó la leyenda negra que hasta hoy se cierne sobre aquel periodo, a través de La Guerra a Muerte (1868), ensayo que popularizó la utilización de aquel término a la hora de referirse a la fase final de este episodio bélico ${ }^{6}$.

Cabe destacar cómo la mayoría de las obras de este periodo analizaron detalladamente los entretelones de la guerra, subrayando el carácter personalista del conflicto y el liderazgo carismático de algunos de sus protagonistas. En el caso de la Historia General de Chile, de Barros Arana, la ética liberal e ilustrada de un Bernardo O’Higgins o un José de San Martín contrastaban con el carácter conspicuo y reaccionario de los últimos gobernadores coloniales. En el caso de La Guerra a Muerte, de Vicuña Mackenna, el personaje central es “(...) un salteador criollo, hijo de un carcelero, que se adueña de la mitad de la República y amenaza conquistarla toda entera" ${ }^{\text {, }}$, frente al coraje y valentía de un liberal Ramón Freire, o la mesura y concordia de un conservador José Joaquín Prieto. La popularidad de este último relato no solo se vio potenciada por la retórica positivista, sino también por la profunda sensibilidad de Vicuña Mackenna a la hora de representar el carácter subalterno de aquellas colectividades,

Como poder político y como constitución social, como denuedo personificado, en sus soldados; y como fanatismo, encarnado en su clero;

\footnotetext{
${ }^{5}$ Estos últimos trabajos -los menos conocidos- han sido compilados en Guillermo Feliú Cruz, XVI Conversaciones Históricas de Claudio Gay con algunos de los testigos y actores de la Independencia de Chile, 1808-1826 (Santiago: Andrés Bello, 1965); Claudio Gay, Usos y costumbres de los araucanos (Santiago: Taurus, 2018).

${ }^{6}$ Diego Barros Arana, Estudios históricos sobre Vicente Benavides y las campañas del sur. 1818-1822 (Santiago: Imprenta de Julio Belin y Compañía, 1850); Benjamín Vicuña Mackenna, La guerra a muerte. Memoria sobre las últimas campañas de la independencia de Chile, 1819-1824 (Santiago: Imprenta Nacional, 1868).

${ }^{7}$ Vicuña Mackenna, La guerra a muerte, $\mathrm{xv}$.
} 


\section{Paternalismo, violencia y economía moral en la frontera austral del imperio español durante las campañas militares contrainsurgentes, 1813-1822}

como ignorancia adueñada de las masas y como barbarie misma, atada a las lanzas fronterizas, la Península entre nosotros era el Sur. Eran las fronteras y sus plazas fuertes; era Valdivia y su real situado; era, en fin, el archipiélago, apéndice inmediato de la corona del reino del Perú.

Allí, en efecto, estaban sus adustos capitanes y sus abolengos militares; allí su clero rudo pero varonil; allí sus frailes de la propaganda y sus misioneros de indígenas, apóstoles de la doctrina de un rey que equiparaban a Dios; allí sus lenguaraces y sus caciques asalariados por el real erario; allí, por fin, las tradiciones, los gustos, los absurdos, las necesidades seculares de la colonia, y todo eso a la par con un ínclito heroísmo que, a virtud de una eterna rebelión, había creado a nuestro Mediodía una existencia excepcional en Chile y aun en todas las Indias de que fue señora la conquista ibérica"8.

Coincidentemente, un siglo más tarde, Mario Góngora llegaría a reflexiones similares, al identificar el desarrollo del vagabundaje y el bandidaje, propios de todo el mundo colonial, como la expresión de un modo de vida -una economía moral, diríamos hoy- asociada a la actividad agraria y pastoril. De ahí que, a su juicio, fenómenos como el inquilinaje y el afianzamiento de la frontera agraria en el valle central chileno habrían potenciado la migración de sujetos populares a las zonas cordilleranas, cuya configuración natural les habría dotado de un sello distintivo, asociado con el nomadismo y la vida en la montaña 9 .

Si bien hay que señalar que la impronta decimonónica se ha mantenido fuertemente enraizada hasta nuestros días, desde fines del siglo pasado es posible ver el surgimiento de una serie de interpretaciones de carácter revisionista, las que desde distintos ángulos y puntos de vista han venido cuestionando muchos de los planteamientos teleológicos y esencialistas heredados de la centuria anterior.

Especial relevancia han tenido los aportes de la llamada nueva historia social chilena -directa heredera de la vertiente anglosajona- aunque con una proyección mucho

\footnotetext{
${ }^{8}$ Vicuña Mackenna, La guerra a muerte, $\mathrm{xx}$.

${ }^{9}$ Mario Góngora, Vagabundaje y sociedad fronteriza en Chile (siglos XVII a XIX) (Santiago: Universidad de Chile, 1966), 33-34.
} 


\section{Manuel Ramírez Espíndola}

más tardía que la de otros países latinoamericanos. A finales de la década de 1990, Ana María Contador publicó el primer estudio sistemático sobre la guerrilla de los hermanos Pincheira ${ }^{10}$, aplicando el modelo del bandido social de Eric Hobsbawm. Las críticas surgieron de inmediato, de la mano de uno de los mayores exponentes de la historiografía tradicional chilena. En un virulento ataque personal a Contador, Sergio Villalobos repitió el catecismo de los historiadores decimonónicos, al señalar que el conflicto bélico había pasado de "banderas idealistas" a "crueldades irracionales", estas últimas protagonizadas por “(...) jefes indígenas, movidos por la revanchas (sic) y el pillaje”, bien por una "ruda sociedad fronteriza" y la "personalidad anormal de aquellos jefes". Sin profundizar aquellas aseveraciones, Villalobos se dedicó a revisar la sintaxis y la estructura gramatical de la obra de Contador, denostando así sus capacidades personales ${ }^{11}$.

Con todo, el giro historiográfico prosperó. Un par de años después, Igor Goicovich analizó los efectos del proceso independentista en los grupos subalternos del Norte Chico, ahondando en sus tesis estructuralistas en torno al papel de la violencia y la criminalidad rural, como fenómenos sintomáticos de la relación entre el estado y el mundo popular ${ }^{12}$. Durante los años siguientes, se hicieron diversas aproximaciones al problema, especialmente desde la perspectiva de las sociedades indígenas -precisamente en la frontera mapuche- y en el marco de los procesos generales que trajo consigo la instauración del Estado nación chileno ${ }^{13}$.

\footnotetext{
10 Ana María Contador, Los Pincheira. Un caso de bandidaje social. Chile 1817-1832 (Santiago: Bravo Allende Editores, 1998).

${ }^{11}$ Sergio Villalobos, "Los Pincheira. Un caso de bandidaje social. Chile 1817-1832. Ana María Contador, Bravo Allende Editores", Cuadernos de Historia, no. 17 (1997): 243-244.

12 Igor Goicovich, "Conflictividad social y violencia colectiva en Chile tradicional. El levantamiento indígena y popular de Chalinga (1818)", Revista de Historia Social y de las Mentalidades, no. 4 (2000): 60-62.

${ }^{13}$ Jorge Pinto, La formación del Estado y la nación, y el pueblo mapuche. De la inclusión a la exclusión (Santiago: Dibam; Centro de Investigaciones Diego Barros Arana, 2003); Geraldine Abarca Cariman, Rupturas y continuidades en la recreación de la cultura mapuche en Santiago de Chile (La Paz: Pinseib; Proeib Andes; Plural Editores, 2005); Amado Laskar, Lo chileno en tierra Mapuche. Héroes de pluma (Santiago: Mosquito Comunicaciones, 2007); Augusto Samaniego Mesías y Carlos ${ }^{\circ}$ Ruiz Rodríguez, Mentalidades y políticas wingka: Pueblo mapuche, entre golpe y golpe (De Ibáñez a Pinochet) (Madrid: CSIC, 2007); José Bengoa, Mapuche, colonos y Estado Nacional (Santiago: Catalonia, 2017).
} 


\section{Paternalismo, violencia y economía moral en la frontera austral del imperio español durante las campañas militares contrainsurgentes, 1813-1822}

Sin duda, una de las visiones más acabadas en torno nuestro tema es la que desarrolló Leonardo León, condensada en un voluminoso libro titulado Ni patriotas ni realistas. El bajo pueblo durante la independencia de Chile (León, 2012). Allí el autor realizó una profunda crítica a la historiografía tradicional, al tiempo que integró los distintos aportes de la nueva historia social, que ya por ese entonces comenzaba a prestar mayor atención al proceso de independencia ${ }^{14}$. En este sentido, la singularidad de su trabajo radicó en haber puesto la mirada al problema específico de la guerra, a través de un amplio marco documental y un enfoque cercano al modelo de la economía moral y la microhistoria.

Por lo demás, al igual que sus correligionarios, León estableció una relación dualista entre una amplia gama de sujetos encasillados en las categorías de "bajo pueblo" y "patriciado", destacando su carácter asimétrico y dicotómico. A su juicio, la idea de la independencia habría sido ajena a los intereses del mundo popular, por lo que la deserción, la violencia y la insurrección habrían sido la genuina expresión de aquella relación antagónica. En su afán por sustentar esta tesis, su investigación no deja de presentar serias falencias, como su estrecho marco temporal y espacial -a través del estudio de los llamados "cuerpos de la patria", en el valle central- sin adentrarse en la matriz del fenómeno guerrillero en la frontera. En una investigación inconclusa, León pretendió luego abordar el desarrollo particular de estos grupos durante la "guerra a muerte", a través de la noción de "montoneras populares"; un concepto a medio camino entre el bandido social y el idealizado mundo popular de la nueva historia social chilena ${ }^{15}$.

De lo anterior, se colige que en la actualidad se siga analizando a estos grupos bajo presupuestos eminentemente esencialistas. La dicotómica relación entre plebe y

\footnotetext{
${ }^{14}$ Gabriel Salazar, Construcción de Estado en Chile (1800-1837) (Santiago: Sudamericana, 2005); Julio Pinto y Verónica Valdivia, ¿Chilenos todos? La construcción social de la nación (1810-1840) (Santiago: Lom, 2009).

${ }^{15}$ Leonardo León, "El difícil dilema de sobrevivir entre dos patrias: el bajo pueblo chileno entre Chacabuco y Maipú, 1817”, Cuadernos de Historia 29 (2008): 33-66; "La República patricia frente al abismo plebeyo: Chile, 1818”, Tiempo Histórico 1 (2010): 107-132; “Montoneras populares durante la gestación de la República, Chile: 1810-1820”, Anuario de Estudios Americanos, 68:2 (2011): 483-510.
} 


\section{Manuel Ramírez Espíndola}

patriciado -y sobre todo la violencia explícita que suele atribuirse a los primeros-induce a pensar que los sujetos populares carecían de una cultura política y que su accionar durante la guerra solo pudo estar mediado por un movimiento de "eterna rebelión" hacia las clases dominantes. Como revelan otros casos similares ${ }^{16}$, ni todos los sectores subalternos participaron en la guerra, ni quienes sí lo hicieron actuaron precisamente bajo principios insurreccionales. Por cierto, cabría poder explicar qué sucedió en las regiones más australes, en Valdivia y Chiloé, donde no se produjeron levantamientos populares, pese a las numerosas exacciones y levas implementadas por las distintas autoridades, tanto realistas como patriotas. Por el contrario, según parece, muchos de estos conglomerados sociales participaron activamente en la guerra, sobre todo a través de la conformación de cuerpos militares y un sentido de identificación con la monarquía que se extendió hasta bien entrado el siglo XIX.

\section{De la depredación a la acumulación. Guerra y fiscalidad durante la campaña 1813-1814}

En marzo de 1813 una fuerza militar de ocupación, orquestada por el virrey Abascal, pero formada enteramente a costa de las guarniciones de Valdivia y Chiloé, desembarcó en Concepción con la finalidad de suprimir el creciente poderío de las juntas de Santiago y esta última ciudad. Tras un par de enfrentamientos en el límite de ambas intendencias, la división realista acabó replegándose al poblado de Chillán, donde permaneció sitiada por los insurgentes hasta finales de ese año.

La indefensión del ejército virreinal se debió no solo a la muerte natural de su General, el brigadier Antonio Pareja, sino a una serie de factores operacionales y

\footnotetext{
${ }^{16}$ Peter Guardino, Peasants, Politics and the Formation of Mexico's National State. Guerrero, 1800-1857 (Stanford: Stanford University Press, 1996); Eric Van Young, The Other Rebellion. Popular Violence, Ideology, and the Mexican Struggle for Independence, 1810-1821 (California: Stanford University Press, 2001).
} 


\section{Paternalismo, violencia y economía moral en la frontera austral del imperio español durante las campañas militares contrainsurgentes, 1813-1822}

logísticos, relativos a la falta de numerario y la incapacidad de sostener a un ejército de ocupación. De hecho, al momento de producirse la invasión, los caudales de la Real Hacienda de Concepción -unos 30.000 pesos- fueron sustraídos y transportados con dirección a la capital ${ }^{17}$, lo que acabó con las aspiraciones de los monarquistas de hacerse con aquella fuente de ingresos. Dicha situación condujo a la imposición de una serie de exacciones y empréstitos entre la población que, según uno de los líderes insurgentes, habrían alcanzado los 80.000 pesos $^{18}$.

Cierto o no -pues no hay registro de tales requerimientos- sabemos que las autoridades optaron por minimizar el impacto negativo que arrastraban este tipo de exacciones, optando por la transferencia directa entre caudales públicos y el control de la administración fiscal a lo largo de la intendencia. De esta manera, en los 18 meses siguientes a la ocupación de Concepción, el mando militar incautó los caudales de la Renta de Tabacos de Concepción, Chillán y Talca, por un monto de 36.628 pesos. La cuantía de aquellos decomisos pudo ser indudablemente mayor, si consideramos que buena parte de las transferencias se hicieron en producto, destinándolas tanto para el consumo de la oficialidad y la tropa como para su comercialización entre la población. De acuerdo con las recaudaciones oficiales, durante el primer año de la guerra, el ejército había incautado alrededor de 3.038 mazos de tabaco - unas 2,7 toneladas de yerba- cifra que casi se duplicó durante el año siguiente. De esta manera, a lo largo de aquella primera campaña, se requisaron cerca de 8.979 mazos de tabaco, correspondientes a más de 8,2 toneladas, avaluadas entre 4.500 y 13.500 pesos (ver gráfica 1).

Gráfica 1. Transferencias de la Administración de Tabacos y Rentas Unidas de la intendencia de Concepción y el partido de Talca al Ejército Real, 1813-1814

\footnotetext{
${ }^{17}$ CHDIC, Vol. X, 303-382.

${ }^{18}$ CHDIC, Vol. I, 95.
} 


\section{Manuel Ramírez Espíndola}

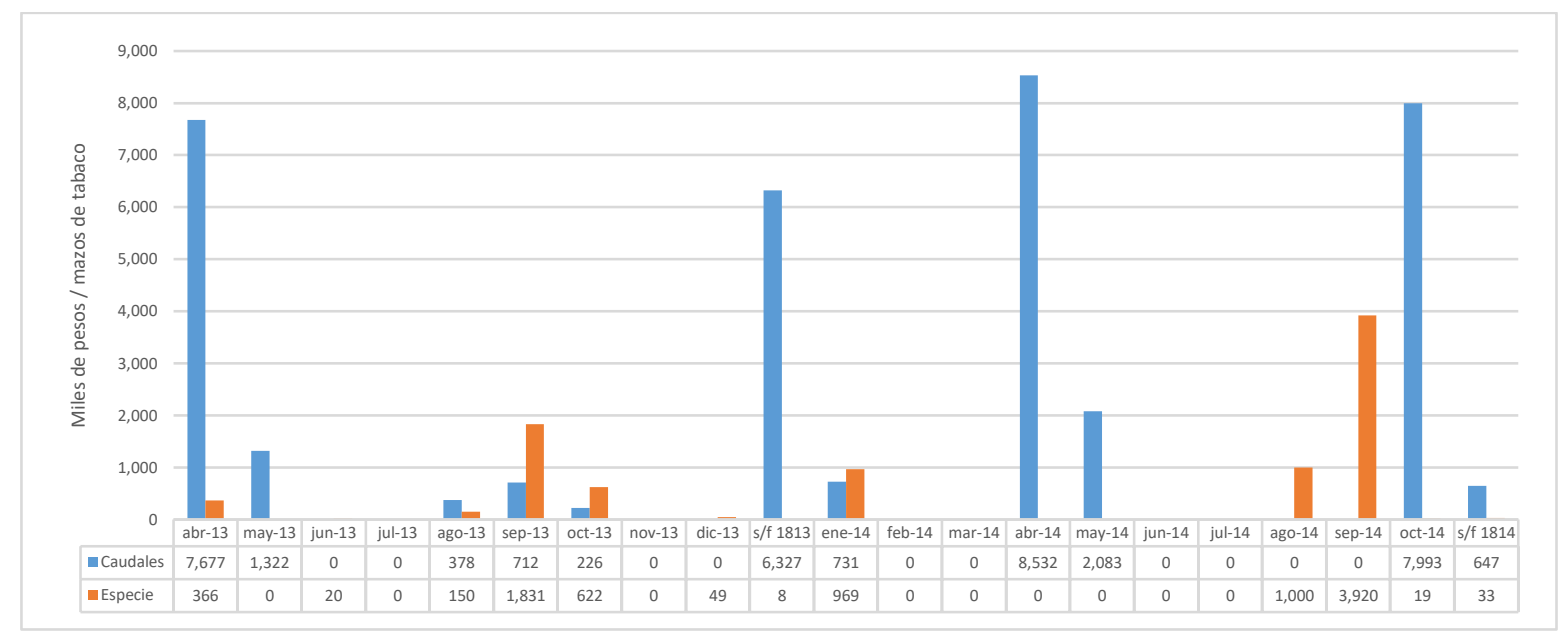

Fuente: FMG, Leg. 8

A fin de sistematizar los distintos decomisos, durante el sitio de Chillán, las autoridades realistas organizaron luego una "Caja Militar Provisional"; una suerte de fusión entre la Real Hacienda, la Renta de Tabacos y la Intendencia Militar, la que concentró las distintas fuentes de recaudación, de cara a la financiación de la división sitiada. En tales circunstancias, y tan solo un par de meses antes, los arquitectos de aquel esquema -el coronel Juan Francisco Sánchez y el intendente militar, Matías de la Fuentehabían creado una "Renta Provisional de licores", a través de la cual pretendían controlar tanto la comercialización como el abasto de las bebidas alcohólicas en el radio urbano de la ciudad. Para ello, el intendente de la Fuente creó un reglamento en el que se detallaba la naturaleza y los procedimientos del nuevo estanco, nombrando así mismo a una serie de individuos idóneos para este fin ${ }^{19}$.

Al igual como habían hecho con la gestión de los tabacos, se designaron administradores entre funcionarios anteriormente exonerados de la Real Hacienda, al tiempo que se dispusieron a varios jefes de guerrilla, a cargo de la incautación de los vinos y aguardientes de las haciendas del partido. De esta manera, en un periodo de 6 meses,

${ }^{19}$ Ordenanza. Chillán, 20 de septiembre de 1813. FMG, Leg. 8, 5. 


\section{Paternalismo, violencia y economía moral en la frontera austral del imperio español durante las campañas militares contrainsurgentes, 1813-1822}

entre octubre de 1813 y marzo de 1814, los monarquistas lograron hacerse con cerca de 2.084 arrobas de vino y aguardiente - unos 33.614 litros- cuyo comercio generó alrededor de 4.773 pesos. Con todo, cabe destacar que las proyecciones originales eran de 4.000 arrobas y una ganancia entre 8.000 y $12.000 \operatorname{pesos}^{20}$, por lo que es posible inferir una posible manipulación de las cifras declaradas (ver gráfica 2).

Gráfica 2. Ingresos de la Renta Provisional de Licores de Chillán, octubre de 1813marzo de 1814

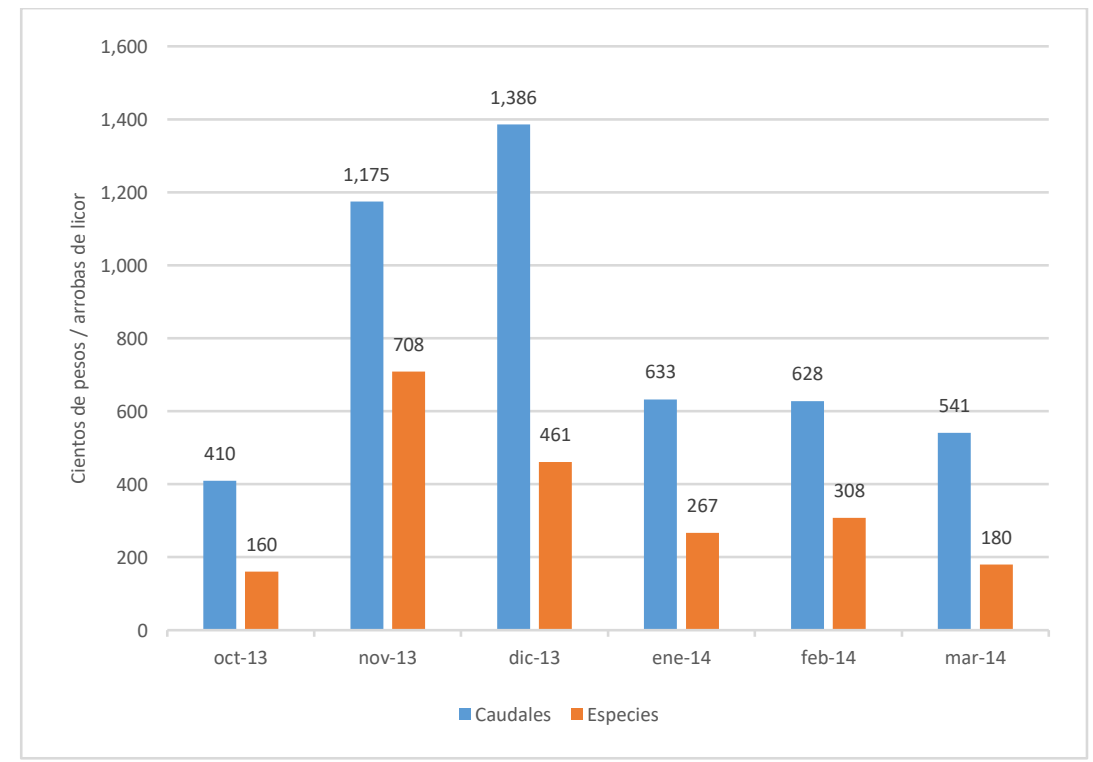

FUENTE: FMG, Leg. 8

Tras el fin del sitio de Chillán y previo a la llegada de las divisiones de Gaínza y Osorio, despachadas directamente desde el Perú, la Caja Provisional extendió estas diligencias a buena parte de la intendencia. A este respecto, a fines de 1813, se establecieron los primeros secuestros de propiedades y caudales de familias

\footnotetext{
${ }^{20}$ De Juan Francisco Sánchez a Matías de la Fuente. Chillán, 11 de septiembre de 1813. FMG, Leg. 8, 5.
} 


\section{Manuel Ramírez Espíndola}

comprometidas con el enemigo, sobre todo en Chillán y Concepción. Paralelamente, se implementaron préstamos forzosos, tanto entre vecinos como entre comunidades eclesiásticas. En el caso de Chillán, ya durante el sitio, se habían establecido distintas nóminas de deudores de censos y capellanías, correspondientes a los conventos de Santo Domingo y la Merced, por cerca de $6.741 \operatorname{pesos}^{21}$. Lo mismo se hizo con los comerciantes locales, sobre todo con quienes realizaban transacciones rumbo a Concepción o Santiago, para lo cual se ordenó la incautación de más de 14.375 pesos en octubre de $1813^{22}$.

La generalización del régimen de exacciones contó con el abierto apoyo de algunos vecinos notables. En este sentido, una estrategia común de estos individuos, desde los primeros días del sitio, fue la de ofrecer préstamos voluntarios, aduciendo a su fidelidad y compromiso con el régimen. Por ejemplo, en junio de 1813, Elías Guerrero, vecino de Chillán, ofreció “depositar” en las Cajas Reales 1.200 pesos pertenecientes a su esposa;

(...) con cargo de su oportuno reintegro por las [cajas] de la capital de Lima o las de las provincias de Chiloé o Valdivia según me sea más conveniente a entregarse a mí o quien mi poder tuviere dándoseme para el efecto la certificación de estilo por duplicado. $^{23}$

Lo cierto es que este tipo de operaciones se diferenciaban considerablemente de las anteriores, pues eran otorgadas espontáneamente por la población civil, lo que les permitía negociar los mecanismos de pago y compensación, evadiendo así cualquier forma de requisición forzosa, así como la aplicación de cargas o imposiciones adicionales. Si a lo anterior sumamos el hecho que funcionaban en calidad de depósitos, con la

\footnotetext{
${ }^{21}$ Extracto de los sujetos pudientes que deben pagar los principales de los fundos que tienen asignados en sus haciendas y casas, según el escrupuloso examen judicial que se ha hecho por el subdelegado del partido y por esta Intendencia. Chillán, 18 de diciembre de 1813. FMG, Leg. 8, 10.

${ }^{22}$ Razón de los individuos residentes en esta ciudad que se hallan debiendo a los comerciantes de la Capital de Santiago, a los de la ciudad de Concepción, y a varios particulares de esta de Chillán. Chillán, 18 de diciembre de 1813. FMG, Leg. 8, 13.

${ }^{23}$ De Elías Guerrero al general Francisco Sánchez. Chillán, 16 de junio de 1813. FMG, Leg. 8, 1.
} 


\section{Paternalismo, violencia y economía moral en la frontera austral del imperio español durante las campañas militares contrainsurgentes, 1813-1822}

posibilidad de ser retirados en distintas ciudades del virreinato, constituían una buena forma de resguardar sus capitales.

A la hora de evaluar los resultados de las políticas fiscales implementadas por el ejército monarquista durante la exitosa campaña 1813-1814, la opinión de sus artífices era un tanto ambivalente. Por un lado, cuestionaban los enormes gastos en los que había incurrido el ejército, absorbiendo más de 1.000 .000 de pesos en poco más de un año de conflicto $^{24}$. Sin embargo, también justificaban la forma en la que se habían generado dichos excesos, sopesándolos con la gesta de haber sobrevivido a un riguroso sitio y derrotado a un enemigo superior en número y recursos;

(...) Bastaba solo recordar la clase de guerra que hemos tenido en este reino y especialmente cuando el Ejército se refugió en Chillán. Todo faltaba allí y solo abundaba la constancia. Aquel ejército más bien pudo llamarse tropa colecticia, llena sí de entusiasmo y heroísmo, procurándose la subsistencia a la par de sus victoriosas ocurrencias y reencuentros. No era una guerra de nación a nación, sino muy semejante a la de los primitivos tiempos de la conquista, y las presas y represas que diariamente hacían las partidas volantes no se repartían como entonces y como se ha hecho en la Península entre la tropa, sino que tan generosa como valiente las entregaban en la intendencia o procuraduría para que a todos sirviese. ${ }^{25}$

\section{Las tramas interpersonales de la guerra}

Varias décadas más tarde, las visiones apologéticas en torno al accionar del ejército monarquista durante los primeros años de la guerra seguían resonando en las cabezas de algunos de sus protagonistas. Tal fue el caso de José Rodríguez Ballesteros, quien al final de su vida recordaba:

\footnotetext{
${ }^{24}$ CHDIC, Vol. XXXV, 231.

${ }^{25}$ CHDIC, Vol. XXXV, 359.
} 


\section{Manuel Ramírez Espíndola}

El conocimiento del país que se pisa y del carácter de sus habitantes, es de necesidad para dirigir operaciones con el más seguro acierto. Nada acredita más esta verdad que las empresas de los jefes subalternos en 1813 al mando del general interino don Juan Francisco Sánchez; debido a estos conocimientos fue que alcanzaron a los comandantes guerrilleros en la provincia de Concepción tantas ventajas y resultados favorables. ${ }^{26}$

Esta romántica versión de los ejércitos monarquistas ciertamente contrasta con las lúgubres narraciones que, tiempo más tarde, se hicieron sobre estos mismos grupos. De ahí que, más allá del color de aquellas representaciones, llama la atención la importancia que estos primeros testimonios atribuían a la estrategia guerrillera en el triunfo inicial de aquellos conglomerados. Las dos relaciones antes citadas hacen una clara mención al sprit de corps que envolvía a sus miembros; un espíritu de cuerpo entendido no como una mera identificación institucional, sino en función de las solidaridades sociales que, a su vez, derivaban directamente de las prácticas redistributivas surgidas al amparo de la guerra.

Lo anterior también guarda relación con el rol de las corporaciones e instituciones de antiguo régimen en la articulación de todo un universo de relaciones asociadas a una concepción paternalista y clientelista de la sociedad. Esto nos ayudaría a entender la capacidad que tuvieron los jefes guerrilleros - en su gran mayoría patricios- de cooptar la voluntad de la tropa y las poblaciones civiles en función de objetivos comunes. En una crónica elaborada por los padres del Colegio de Propaganda Fide de Chillán, relativa a las condiciones del sitio, se señalaba;

Deseoso el prelado de darles algún alivio, mandó que un religioso lego fuera el ranchero, y le dio peones para su ayuda y cuidado de aderezarles la comida y repartirles mañana y tarde a cada uno, franqueando para esto el ajuar correspondiente. La plaza sólo daba la carne, con correspondencia al número de individuos; y la comunidad ponía todo lo demás necesario, de legumbres, hortalizas, sal, ají, leña y pan diariamente para todos; pero a los oficiales además del desayuno por la mañana se les asistía con las viandas de la comunidad, como

\footnotetext{
${ }^{26}$ CHDIC, Vol. VI, 3-4.
} 


\section{Paternalismo, violencia y economía moral en la frontera austral del imperio español durante las campañas militares contrainsurgentes, 1813-1822}

a cualquier religioso. Suplía también el colegio leña y luz para los cuerpos de guardia, que en él había, y como el tiempo era el rigor del invierno, y los soldados tenían que hacerla en descubierto y con poca ropa, después que acababan sus dos horas, se les daba un trago de vino bueno para aliviarlos del rigor del frío, y esta solicitud duró por espacio de cinco meses. ${ }^{27}$

Estas cualidades se relacionaban además con el "conocimiento del país", vale decir, la capacidad de aquellos individuos de asociarse entre sí, tanto a nivel vertical -a través de relaciones jerárquicas, basadas en la diferenciación social y el clientelaje- como a nivel horizontal, a través de vínculos de clase, parentesco y paisanaje; “(...) siendo entonces los dos ejércitos únicamente compuestos de chilenos realistas y chilenos patriotas, según se denominaban, teniendo el ejército patrio más españoles que europeos a su servicio que los que tenía el ejército real". ${ }^{28}$

Finalmente, cabría que agregar el "capital relacional" de los distintos jefes guerrilleros, cuyas trayectorias vitales son, en este sentido, bastante ilustrativas. Los hermanos Luis y Francisco Borja Urrejola, hacendados y diezmeros del partido de Chillán, eran miembros de una de las familias más pudientes del obispado, destacándose por su abierto compromiso con la causa monarquista. Su padre, Alejandro Urrejola, había amasado una pequeña fortuna en el comercio y la agricultura, ocupando la alcaldía de Concepción en varias ocasiones. Sus pasos en la corporación edilicia fueron seguidos por Francisco Borja, primero como procurador, luego como síndico y, finalmente, como regidor, empleo que mantuvo hasta 1811, cuando una junta revolucionaria lo despojó del cargo $^{29}$. Ese mismo año, otro de los hermanos, Agustín -quien servía como canónigo magistral de la catedral de Concepción- fue electo diputado del Congreso Nacional, cargo al que también accedió Luis, en calidad de diputado suplente. Lo cierto es que, poco tiempo después, ambos serían exonerados de dicha asamblea, aludiendo a su marcada filiación política. Tras el estallido de la Guerra, Agustín fue deportado a Lima, donde

\footnotetext{
${ }^{27}$ CHDIC, Vol. IV, 45.

${ }^{28}$ CHDIC, Vol. VI, 4.

${ }^{29}$ ACC, Lég.1, fj. 100.
} 


\section{Manuel Ramírez Espíndola}

prosiguió con su carrera eclesiástica, mientras que el resto de los hermanos sirvieron en el ejército, como proveedores y jefes de guerrilla. Durante el funcionamiento de la Renta de Licores, Luis y Francisco Borja controlaban la totalidad de aquellos decomisos, sirviéndose sobre todo de arrieros y parcialidades pehuenches, las que obraban bajo su mando. Evidentemente, el estatus económico y social de aquella familia al interior del partido de Chillán nos ayudan a explicar su posición privilegiada en aquellas operaciones. $\mathrm{Su}$ hacienda, Cucha-Cucha, fue el epicentro de las guerrillas monarquistas, las que siguieron operando allí incluso tras la caída del gobierno español en 1817. Para ese entonces, Luis y Agustín se hallaban cosechando sus logros personales en la Península, al tiempo que el resto de la familia permanecía exiliada en Lima.

Si bien la mayor parte del patrimonio económico familiar de los Urrejola se perdió en el curso de aquellos enfrentamientos ${ }^{30}$, la impronta de sus primeras formaciones guerrilleras fueron el caldo de cultivo para el desarrollo de las futuras "montoneras populares", durante la llamada "guerra a muerte". De hecho, la famosa guerrilla de José María Zapata, desplegada entre 1817 y 1820, en alianza con las parcialidades pehuenches, tuvo su origen en las actividades contrainsurgentes de la hacienda Cucha-Cucha, de la que provenía el propio Zapata ${ }^{31}$. Un caso similar nos lo ofrece la guerrilla de los hermanos Lantaño, en torno a la hacienda El Roble, en el partido de Chillán, así como la de los hermanos Pincheira, en la estancia precordillerana de Cato. El eje articulador de todas estas formaciones se hallaba en la hacienda, la que desde finales del siglo XVIII venía experimentando un fuerte proceso de militarización, a través de la formación de milicias disciplinadas, generando una nueva relación de dependencia entre patrones e inquilinos. Lo anterior podría explicar la emergencia del fenómeno guerrillero en la región, aunque creemos que valdría la pena analizar en mayor profundidad el entramado relacional de

\footnotetext{
${ }^{30}$ Leonardo Mazzei, "Terratenientes de Concepción en el proceso de modernización de la economía regional en el siglo XIX”, Historia, no. 31 (1998): 182-186.

${ }^{31}$ Leonardo León, "Montoneras populares", 495-496; Manuel Ramírez, "Violencia y Guerrillas durante la independencia de Chile. El sitio de Talcahuano, 1817-1818", en Chile y España, primera mitad del siglo XIX: Chile, consolidación republicana. España, liberalismo y restauración, ed. Andrés Medina Aravena (Concepción: Universidad Católica de la Santísima Concepción; Universidad de Salamanca, 2014), 84-86.
} 


\section{Paternalismo, violencia y economía moral en la frontera austral del imperio español durante las campañas militares contrainsurgentes, 1813-1822}

estos grupos, considerando el rol que estos tuvieron en la movilización del mundo indígena ${ }^{32}$.

Un segundo caso significativo de este periodo es el de Vicente Antonio Bocardo, ampliamente conocido por ser uno de los líderes emblemáticos de la "guerra a muerte". Si bien Vicuña Mackenna lo representa como un sujeto oscuro, no era ningún advenedizo. Por el contrario, pertenecía a dos importantes clanes de militares borbónicos. Su padre había sido capitán en el Batallón de Infantería Chile ${ }^{33}$, mientras que por el lado materno se hallaba ligado con el acaudalado clan de los Santa María, por ese entonces radicado en la capital del reino. Al igual que los Urrejola, Bocardo pertenecía a una generación joven, por lo que no se hallaba plenamente vinculado en la política ni los negocios al momento de estallar la crisis imperial. Tras el inicio de la guerra se unió a las filas monarquistas, también como aprovisionador del ejército ${ }^{34}$, lo que complementó con labores de espionaje, así como en la creación de guerrillas en el partido de Rere ${ }^{35}$.

Tras el fin de la campaña 1813-1814, y en premio a sus servicios, ingresó al cabildo de Concepción en calidad de alférez real y alcalde de primer voto, donde permaneció hasta $1816^{36}$. Allí reforzó sus lazos económicos con otros capitulares, entre los que destacan José Cruz Urmeneta y Manuel Rioseco, con quienes estableció una serie de fianzas relativas al cobro de los diezmos de Rere y San Carlos de Purén ${ }^{37}$.

En este sentido, el análisis de sus actividades en aquellos distritos nos ayuda a formarnos una idea más clara en torno a su rol durante los años de la "Guerra a Muerte", pues sabemos que durante este periodo fue precisamente él quien organizó la retirada de aquellas poblaciones rumbo a la frontera indígena. De acuerdo con los testimonios recopilados por Claudio Gay, en 1819 Bocardo había logrado con éxito reunir a más de 4

\footnotetext{
${ }^{32}$ Una aproximación reciente a este problema en Pilar Herr, Contested Nation. The Mapuche, Bandits, and State Formation in Nineteenth-Century Chile (Albuquerque: University of New Mexico Press, 2019).

${ }^{33}$ SIMANCAS, SGu, Leg. 7266,6, fj. 789.

${ }^{34}$ CHDIC, Vol. XXXV, 263

${ }^{35}$ CHDIC, Vol. I, 242.

${ }^{36}$ ACC, Leg. 1, fj. 122.

${ }^{37}$ NCon, Leg. 9, fj. 39.
} 


\section{Manuel Ramírez Espíndola}

mil personas en el inexpugnable valle de Quilapalo, al sur del río Bio-bio, donde estableció una suerte de sistema comunitario, de cara al comercio con las parcialidades indígenas y la actividad guerrillera contra las fuerzas republicanas, hasta su rendición en $1822^{38}$.

Los casos antes mencionados solo constituyen un ápice de un fenómeno ampliamente generalizado durante estos años. Ciertamente, la mancomunión de todos estos individuos y sus complejas redes clientelares con los sujetos populares fueron un factor decisivo en el curso de los procesos de insurrección social presentes en la frontera al finalizar el primer cuarto del siglo XIX. Sin embargo, conviene recalcar cómo su accionar estuvo fuertemente condicionado por una suerte de racionalidad heredada de los primeros años del conflicto. De ahí que las prácticas fiscales y militares improvisadas durante la guerra constituyeron un cúmulo de experiencias para el periodo posterior, tanto en el accionar de los nuevos ejércitos republicanos como en el seno de los últimos baluartes realistas.

\section{A modo de conclusión: guerrillas, bandidaje y economía moral}

Probablemente, el problema más grande que tenemos los historiadores a la hora de hablar de las guerrillas del periodo independentista sea la percepción decimonónica de vincularlas con el bandidaje. Lo cierto es que, hace ya más de medio siglo, Mario Góngora señalaba la necesidad de analizar la relación simbiótica entre estas dos dimensiones ya que, si bien las guerrillas tenían una organización y unos objetivos diametralmente distintos a los del bandolerismo, a la larga, ambas acababan retroalimentándose $\mathrm{e}^{39}$.

No debemos olvidar que las guerrillas, propiamente tales, constituían una táctica ampliamente difundida entre los ejércitos del nuevo y el viejo mundo. De ahí que aquellas

\footnotetext{
${ }^{38}$ Gay, XVI Conversaciones, 41-44.

${ }^{39}$ Góngora, Vagabundaje y sociedad fronteriza, 32-33.
} 


\section{Paternalismo, violencia y economía moral en la frontera austral del imperio español durante las campañas militares contrainsurgentes, 1813-1822}

formaciones cumplían con un rol auxiliar al de los ejércitos, poseían una estructura jerárquica y se hallaban lideradas por oficiales veteranos o de milicias los que, a su vez, formaban parte de la institucionalidad castrense. Lo cierto es que tanto su composición como su modus operandi no diferían mucho de las tradicionales gavillas y el bandolerismo. De hecho, en situaciones excepcionales, como las guerras, las autoridades se hacían del apoyo de estas últimas a la hora de desplegar sus respectivos contingentes. De esta forma, dichas asociaciones se convertían en un blanco fácil para las fuerzas opositoras, las que estigmatizaban a sus miembros y criminalizaban su accionar, alimentando así el mito que secularmente se ha tejido en torno a estos grupos.

Dicho de otra manera, las representaciones que hasta el día de hoy se han hecho respecto a las guerrillas de este periodo no guardan directa relación con su verdadera naturaleza, por lo que no cabría interpretar sus acciones como actos puramente arbitrarios o antojadizos. Por el contrario, la mayor parte de las acciones guerrilleras se hallaban directamente circunscritas al mandato de sus respectivas jefaturas las que, a su vez, actuaban idealmente sobre consideraciones logísticas, bien por intereses personales o de su grupo más cercano. En este sentido, las guerrillas operaban bajo una cierta racionalidad emanada de las instituciones y los intereses de las colectividades que les daban forma, aunque su accionar se relacionaba con un tipo de violencia insurreccional que atentaba directamente contra el poder establecido ${ }^{40}$.

Lo anterior nos ayudaría a explicar los distintos grados de participación de los sujetos populares a lo largo del conflicto, toda vez que su inclusión en los procesos bélicos se hallaba íntimamente mediada por los intereses de los grupos dominantes y, fundamentalmente, por esta suerte de racionalidad en el ejercicio y práctica de la guerra. Ejemplos de este tipo de situaciones se hicieron particularmente visibles durante tres periodos distintivos: Durante la campaña contrainsurgente de 1813-1814; tras la invasión del ejército de los Andes, en 1817; y durante la llamada "guerra a muerte", entre 1819 y 1822. En todas estas coyunturas es posible ver, por un lado, un contexto general de

\footnotetext{
${ }^{40}$ Eduardo González Calleja, La violencia en la política (Madrid: CSIC, 2003), 476.
} 


\section{Manuel Ramírez Espíndola}

emergencia bélica originada tras la irrupción de ejércitos de ocupación, lo que dio paso al desarrollo de las guerrillas, las que contaron con un amplio aliciente en el mundo popular, al tiempo que contaban con un dispositivo de poder que les daba legitimidad y aseguraba su supervivencia.

Si bien el estudio comparado de las distintas coyunturas bélicas revela la necesidad de situar los objetivos y alcances de cada fenómeno guerrillero, hay que recalcar que las distintas dirigencias político-militares, a lo largo de todo el periodo en cuestión, hicieron uso de las guerrillas como una forma de sostener el creciente gasto militar. Para ello, sus artífices diseñaron verdaderos proyectos fiscales, los que ciertamente institucionalizaron las prácticas guerrilleras de cara a la posguerra.

\section{FUENTES}

ACC. Archivo Nacional de Chile. Sección Cabildos y Municipalidades. Municipalidad de Concepción.

CHDIC. Archivo Nacional de Chile. Colección de Historiadores y de documentos relativos a la independencia de Chile

FMG. Archivo Nacional de Chile. Fondo Ministerio de Guerra.

NCon. Archivo Nacional de Chile. Sección Notarios. Notarios de Concepción.

SIMANCAS, SGu. Archivo General de Simancas, Secretaría del Despacho de la Guerra.

\section{REFERENCIAS}

Abarca Cariman, Geraldine. Rupturas y Continuidades En La Recreación de La Cultura Mapuche En Santiago de Chile. La Paz: Pinseib; Proeib Andes; Plural Editores, 2005.

Aguirre, Carlos, and Charles Walker, eds. Montoneros, Abigeos y Malhechores. Criminalidad y Violencia En El Perú, Siglos XVIII-XX. Lima: Instituto de Cooperación Agraria, 1990. 


\section{Paternalismo, violencia y economía moral en la frontera austral del imperio español durante las campañas militares contrainsurgentes, 1813-1822}

Archer, Christon, ed. The Wars of Independence in Spanish America. Wilmington: Jaguar Books, 2000.

Barros Arana, Diego. Estudios Históricos Sobre Vicente Benavides y Las Campañas Del Sur. 1818-1822. Santiago: Imprenta de Julio Belin y Compañía, 1850.

Bengoa, José. Mapuche, Colonos y Estado Nacional. Santiago: Catalonia, 2017.

Contador, Ana María. Los Pincheira. Un Caso de Bandidaje Social. Chile 1817-1832. Santiago: Bravo Allende Editores, 1998.

Echeverri, Marcela. Indian and Slave Royalist in the Age of Revolution: Reform, Revolution, and Royalism in the Northern Andes, 1780-1825. New York: Cambridge University Press, 2016.

Gay, Claudio. XVI Conversaciones Históricas de Claudio Gay Con Algunos de Los Testigos y Actores de La Independencia de Chile, 1808-1826. Editado por Guillermo Feliú Cruz. Santiago: Andrés Bello, 1965.

Gay, Claudio. Usos y Costumbres de Los Araucanos. Editado por Diego Milos. Santiago: Taurus, 2018.

Fisher, John R., Allan J. Kuethe, and Anthony McFarlane, eds. Reform and Insurrection in Bourbon New Granada and Perú. Baton Rouge: Louisiana University Press, 1990.

Goicovic Donoso, Igor. "Conflictividad Social y Violencia Colectiva En Chile Tradicional. El Levantamiento Indígena y Popular de Chalinga (1818)." Revista de Historia Social y de Las Mentalidades, No. 4 (2000): 51-86.

Góngora, Mario. Vagabundaje y Sociedad Fronteriza En Chile (Siglos XVII a XIX). Santiago: Universidad de Chile, 1966.

González Calleja, Eduardo. La Violencia En La Política. Madrid: CSIC, 2003.

Guardino, Peter. Peasants, Politics and the Formation of Mexico's National State. Guerrero, 1800-1857. Stanford: Stanford University Press, 1996.

Halperin Donghi, Tulio. Revolución y guerra. Formación de una élite dirigente en la Argentina criolla. Buenos Aires: Siglo XXI, 1972.

Herr, Pilar. Contested Nation. The Mapuche, Bandits, and State Formation in NineteenthCentury Chile. Albuquerque: University of New Mexico Press, 2019. 


\section{Manuel Ramírez Espíndola}

Katz, Fredrich, ed. Revuelta, Rebelión y Revolución. La Lucha Rural En México, Del Siglo XVI Al XX. México: Ediciones Era, 1990.

Kinsbruner, Jay. Independence in Spanish America: Civils Wars, Revolutions, and Underdevelopment. Albuquerque: University of New Mexico Press, 2000.

Laskar, Amado. Lo Chileno En Tierra Mapuche. Héroes de Pluma. Santiago: Mosquito Comunicaciones, 2007.

León Solís, Leonardo. “E1 Difícil Dilema de Sobrevivir Entre Dos Patrias: El Bajo Pueblo Chileno Entre Chacabuco y Maipú, 1817.” Cuadernos de Historia, No. 29 (2008): 33-66.

León Solís, Leonardo. "Montoneras Populares Durante La Gestación de La República, Chile: 1810-1820." Anuario de Estudios Americanos 68 No. 2 (2011): 483-510.

León Solís, Leonardo. "La República Patricia Frente Al Abismo Plebeyo: Chile, 1818." Tiempo Histórico, no. 1 (2010): 107-132.

McFarlane, Anthony. War and Independence in Spanish America. New York: Routledge, 2014.

Mallon, Florencia E. Peasant and Nation. The Making of Postcolonial Mexico and Peru. Berkeley: University of California Press, 1995.

Mazzei de Grazia, Leonardo. "Terratenientes de Concepción En El Proceso de Modernización de La Economía Regional En El Siglo XIX.” Historia 31 (1998): $179-215$.

Pinto Rodríguez, Jorge. La Formación Del Estado y La Nación y El Pueblo Mapuche. De La Inclusión a La Exclusión. Santiago: Dibam; Centro de Investigaciones Diego Barros Arana, 2003.

Pinto Vallejos, Julio, and Verónica Valdivia. ¿Chilenos Todos? La Construcción Social de La Nación (1810-1840). Santiago: Lom, 2009.

Ramírez Espíndola, Manuel. "Violencia y Guerrillas Durante La Independencia de Chile. El Sitio de Talcahuano, 1817-1818.” In Chile y España, Primera Mitad Del Siglo XIX: Chile, Consolidación Republicana. España, Liberalismo y Restauración, editado por Andrés Medina Aravena. Concepción: Universidad de Salamanca; Ucsc, 2014. 


\section{Paternalismo, violencia y economía moral en la frontera austral del imperio}

español durante las campañas militares contrainsurgentes, 1813-1822

Salazar, Gabriel. Construcción de Estado En Chile (1800-1837); Democracia de Los "Pueblos". Militarismo Ciudadano. Golpismo Oligárquico. Santiago: Sudamericana, 2005.

Samaniego Mesías, Augusto, and Carlos Ruiz Rodríguez. Mentalidades y Políticas Wingka: Pueblo Mapuche, Entre Golpe y Golpe (De Ibáñez a Pinochet). Madrid: CSIC, 2007.

Young, Eric Van. The Other Rebellion. Popular Violence, Ideology, and the Mexican Struggle for Independence, 1810-1821. California: Stanford University Press, 2001.

Vicuña Mackenna, Benjamín. La Guerra a Muerte. Memoria Sobre Las Últimas Campañas de La Independencia de Chile, 1819-1824. Santiago: Imprenta Nacional, 1868.

Villalobos, Sergio. “Los Pincheira. Un Caso de Bandidaje Social. Chile 1817-1832. Ana María Contador, Bravo Allende Editores.” Cuadernos de Historia No. 17 (1997): 243-248. 